\title{
ASSESSING THE EFFECTIVENESS OF PROTECTED AREAS ON FLORISTIC DIVERSITY IN TROPICAL FORESTS
}

\author{
Ekoungoulou, R. ${ }^{1}-$ Folega, F. $^{5}-$ Mukete, B. ${ }^{3}-$ IFo, S. A. ${ }^{4}$-Loumeto, J. J. ${ }^{2}-$ LiU, X. D. ${ }^{1,{ }^{*}}$ \\ NIU, S. K. ${ }^{1, "}$ \\ ${ }^{1}$ Laboratory of Ecological Planning and Management, College of Forestry, \\ Beijing Forestry University, 100083 Beijing, China
}

${ }^{2}$ Département de Biologie et Physiologie Végétales, Faculté des Sciences et Techniques, Université Marien Ngouabi, BP 69 Brazzaville, Republic of Congo

${ }^{3}$ Laboratory of Integrated Analysis, College of Forestry, Beijing Forestry University 100083 Beijing, China

${ }^{4}$ Laboratoire de Géomatique et d'Ecologie Tropicale Appliquée, Département des Sciences et Vie de la Terre, Ecole Normale Supérieure, Université Marien Ngouabi BP 237 Brazzaville, Republic of Congo

${ }^{5}$ Unité de Recherche en Ecologie et Géomatique Appliquée, Laboratoire de Botanique et Ecologie Végétale, Faculté des Sciences, Université de Lomé

BP 1515, Lomé, Togo

*Corresponding authors

e-mail:niushukui@yahoo.com, phone/fax: +86-10-62338100 (NIU, S. K.);

xd_liu@bjfu.edu.cn,phonelfax: +86-10-62336703 (LIU,X. D.)

(Received 23 ${ }^{\text {rd }}$ Aug 2017; accepted $10^{\text {th }}$ Jan 2018)

\begin{abstract}
Understanding major drivers of tree species distribution and tropical forest composition is imperative for biodiversity conservation. This study aimed to assessing the floristic diversity and structure of Lesio-louna forest in southern Republic of Congo and its implications for sustainable development. The measurements were made in six plots: three plots located in the Iboubikro forest and three in Blue Lake Forest (circular plots of $1,256 \mathrm{~m}^{2}$ or $40 \mathrm{~m}$ of plot diameter). 85 trees of DBH $\geq 10 \mathrm{~cm}$, divided into 25 species and 14 families have been recorded. Biomass data was collected using the tree-ring or floristic inventory method and data analyzed using SPSS v.18.0 statistical software. The results showed that, the Fabaceae had significant trees (17 species), with a relative diversity index of $20 \%$ followed by the Mimosaceae with 14 species and a relative diversity index of $16 \%$. Millettia laurentii, Pentaclethra eetveldeana, Eriocoelum macrocarpum, Millettia pinnata and Sorindeia juglandifolia were listed as most important species in the area based on their relative frequency. Further study has been done to identify and determine the trees taxon for Lesio-louna tropical forest and their phytogeographical distribution. Flora of Lesio-louna protected area has a remarkable diversity and the floristic richness is very considerable in its specific composition.
\end{abstract}

Keywords: species diversity, Iboubikro, Blue Lake Forest, Lesio-Louna Forest, tree species

\section{Introduction}

Central African forests comprise the second largest continuous block of tropical forests in the world after the Amazonian forests. These Central African forests harbour up to 20,000 different plant species including 8,000 tree species and store some 200 tons of carbon per hectare in live trees (Fayolle et al., 2014a). Tropical forest ecosystems apart from being carbon sinks are known to harbour over $50 \%$ of terrestrial 
biodiversity (Yoka et al., 2013; FAO, 2016). This is facilitated by biogeophysical microclimatic processes (e.g. arbor coverage) that influence surface albedo, rate of evapotranspiration, temperature and precipitation (Mukete and Sun, 2014). In Central Africa, most timber species require high light levels at the seedling stage for survival and growth (Ouedraogo et al., 2014). Congo basin forests house over of Earth's biodiversity have an important influence on the climate system (Ekoungoulou et al., 2015). Congo basin tropical forests ecosystems in Central Africa play an important role in the global carbon cycle, especially in carbon sequestration (Ekoungoulou et al., 2014a). This carbon results from global warming and is partly linked to anthropogenic activities such as loss in forest cover (FAO, 2008; Ngomanda et al., 2013).

The Republic of Congo is located in Central Africa and with a surface area of $342,000 \mathrm{~km}^{2}$, covered by $65 \%$ dry and moist forests and $35 \%$ grassland and shrub landscapes (Legendre, 2014). However, among the two types of vegetation, there are savannas included in forest zones and the forest features of low savanna areas (Legendre, 2014). Interest in forest biodiversity has recently increased in response to the damage caused to ecosystem by anthropogenic activity.

Regarding the flora of Lesio-louna sanctuary, Nkounkou (2003) mentioned that the grassland is dominated by Hyparrhenia diplandra (Poaceae) and Panicum maximum (Poaceae) and the bushland dominated by Hymenocardia acida (Hymenocardiaceae) and Annona arenaria (Annonaceae). Therefore, the Lesio-louna forests are semi-tropical evergreen forests and are zones of transition between evergreen and semi-deciduous forests (PLL, 2010). These forests are characterized by a complex structure of high plant diversity exhibiting a heterogeneous appearance (Ekoungoulou et al., 2015). The canopy is generally discontinuous with separated tree crowns, dense undergrowth made of both short and tall grasses and lianescentes of Marantaceae, Zingiberaceae and Commelinaceae. Large trees (often commercial species) if present, always exceed $50 \mathrm{~m}$ in height (PLL, 2010), hence their canopy structure and undergrowth are easily distinguishable. This is because woodlands and forests have open Marantaceae with dense undergrowth (Nkounkou, 2003; Ekoungoulou et al., 2014b).

The Lesio-louna natural forest is a contiguous humid closed canopy forest with large areas of savannah and forest-savannah mosaics. These are often composed of forest groves either along the river bank or resulting from ancient local human activities (Ekoungoulou, 2014). The forests are highly dynamic ecosystems already encroaching into the savannah area (Koubouana et al., 2015).

Biodiversity is the integration of the variety and variation of all living organisms as related to their habitats and ecological complexes (CBD, 2006; Mukete and Sun, 2014). With its three primary attributes composition, structure and process, biodiversity is organized into a nested hierarchy from genes to species, populations and ecosystems. But recently, these vital ecosystems are being threatened by population growth and agricultural expansion (Ernst et al., 2013). It has therefore become very imperative to assess the in situ biodiversity such as to better understand its evolution (Yoka et al., 2013). The floristic diversity of a forest is a parametric description of its in-situ plant communities (FAO, 2008). It expresses the richness of a given community relative to its number of families, genus and species. It also takes into account the distribution of the species within the community (consistency or fairness) (Yoka et al., 2013). This can be expressed by several diversity indices with the most frequently used being the ShannonWeaver diversity index (Fedor and Spellerberg, 2013). This index is mostly used for a 
comparative study of populations because it is independent of the size of the studied population (Chen and Li, 2011; Folega et al., 2014).

Species richness is a measure of the variety of species in a sampled area (Ekoungoulou et al., 2017). It is often a representation based simply on a count of the number of species in a particular sample (Fedor and Spellerberg, 2013; Fayolle et al., 2014b). Species diversity can be calculated and expressed in different formats with many indices such as Berger-Parker index, Margalef index, Menhinick index while others are based on complex mathematics (e.g. Brillouin index). Selection of appropriate index depends on required sample size sensitivity (from low in Simpson or Berger-Parker index to high in Margalef index), discriminant ability or simply on how widely an index is applied in ecological (FAO, 2008). Estimating biomass is necessary (Fayolle et al., 2014a) especially for those who stand to benefit from mechanisms such as reducing emissions from deforestation and forest degradation, and forest conservation, sustainable management of forest, and enhancement of forest carbon stocks (REDD+). This is an initiative aimed at encouraging less developed countries to voluntarily reduce their national deforestation rates and greenhouse gas emissions (Ngomanda et al., 2013; Ekoungoulou et al., 2014a). Hence, assessing floristic diversity such as to enable Congo enhance its floristic tank and sustainably manage its forests has become obvious. This study mainly focus on aimed the floristic distribution and structure of a Republic of Congo's tropical equatorial rainforest. It also aimed at assessing the trees composition of the Lesio-louna natural forest in Republic of Congo.

\section{Materials and Methods}

\section{Study area}

The study area is located in Lesio-louna natural forest of the Republic of Congo. It is managed by the Lesio-louna Project supported by The Aspinall Foundation and Congolese Ministry of Forest Economy and Sustainable Development. This is a wildlife reserve that extends over 173,000 ha (PLL, 2010; Ekoungoulou et al., 2014a) right into the country's Teke-plateau. These are a series of plateaus arising from Gabon, crossing the Republic of Congo and ending up in the Democratic Republic of Congo. Studied sites are located between $15^{\circ} 28.353^{\prime} \mathrm{E}, 03^{\circ} 16.241^{\prime} \mathrm{S}$ and $15^{\circ} 28.425^{\prime} \mathrm{E}, 03^{\circ} 16.056^{\prime} \mathrm{S}$ for Ikoubikro and between $15^{\circ} 28.841^{\prime} \mathrm{E}, 03^{\circ} 18.843^{\prime} \mathrm{S}$ and $15^{\circ} 28.919^{\prime} \mathrm{E}, 03^{\circ} 19.032^{\prime} \mathrm{S}$ for Blue Lake Forest (Fig. 1). Average annual rainfall ranges between 1,500 to 2,000 mm (ANAC, 2013) while mean annual temperature ranges between $20^{\circ} \mathrm{C}$ to $35^{\circ} \mathrm{C}$ (ANAC, 2013; Ekoungoulou, 2014; Ekoungoulou et al., 2014b). This gives the Lesio-louna a characteristic tropical equatorial climate with varying long dry seasons and low temperatures (ANAC, 2013; Ekoungoulou et al., 2014a). Meanwhile, the relative humidity ranges from $52 \%$ in August to $92 \%$ in December (Fig. 2) with several rivers such as the Ngambali and Lesio arising from and running through it (PLL, 2010; Ekoungoulou et al., 2015). Humidity data was provided by the main meteorological station around the study area which is from Congo's National Agency of Civil Aviation, Republic of Congo (ANAC, 2013).

\section{Sampling design}

The data regarding this study have been collected from August to October 2012 in Lesio-louna protected area. The double decameter was used (model TAJIMA-20m) 
made by Forestry Suppliers Inc, USA to measure the diameter at breast height (DBH) for each tree at both the Iboubikro and Blue Lake Forests.

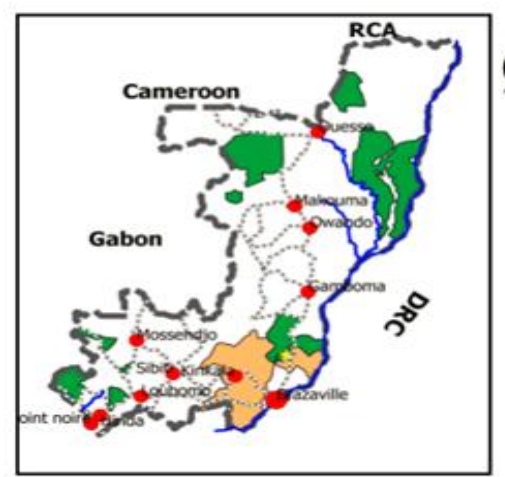

Legend

- Capital city

- Main Localities

Main rivers

- Main roads

country limits

Protected areas

Lesio-Louna

Lefini

Other PA

Pool province

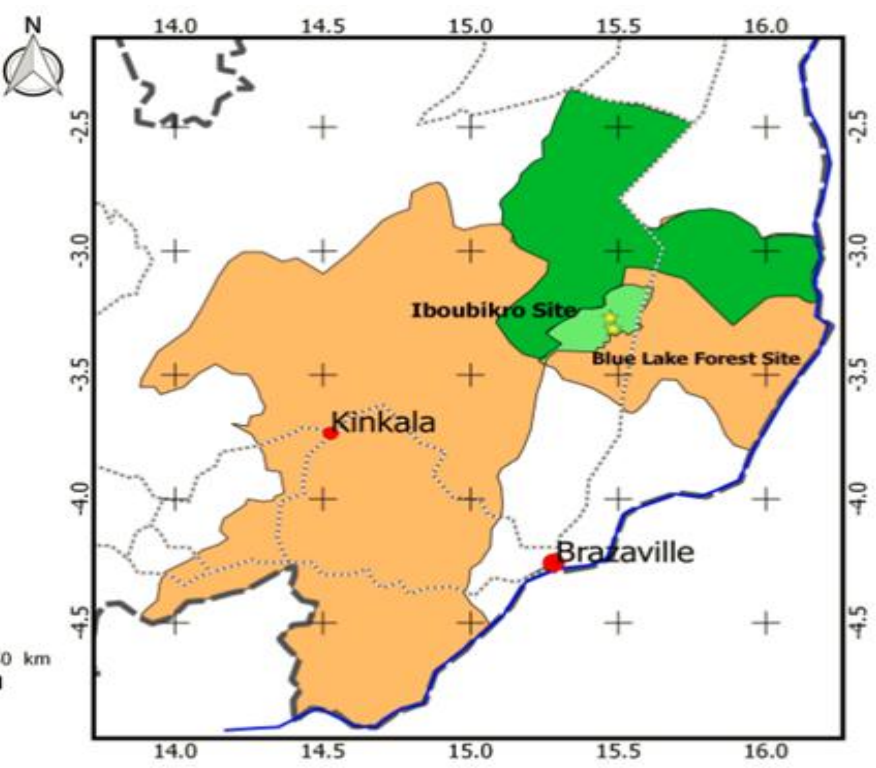

Figure 1. Study area location

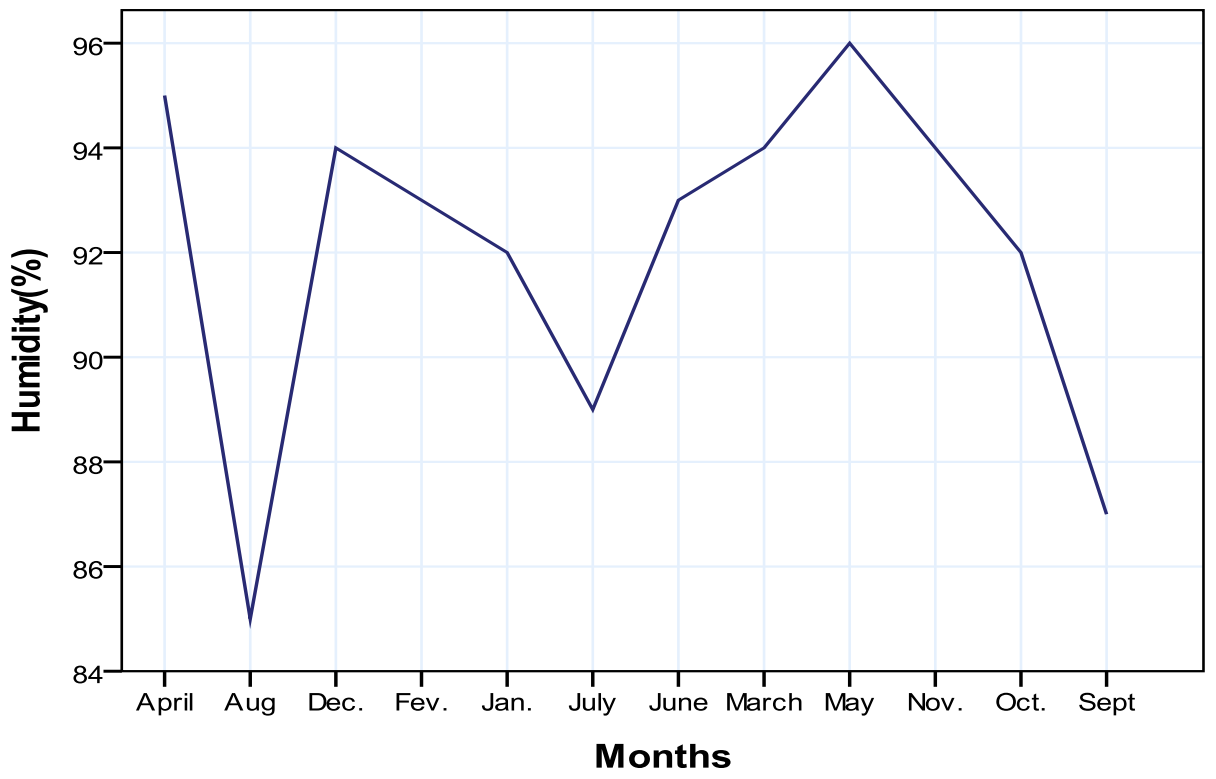

Figure 2. Average Monthly variation of relative humidity in Lesio-louna area from 1990 to 2012

Each forest site was divided into three circular plots of size $1,256 \mathrm{~m}^{2}$ (six plots in all) separated by a $100 \mathrm{~m}$ distance from each other (Table 1). Each circular plot was further divided into three circles (Fig. 3). From the circular plot center to the first circle (small circle), the radius was $0-6 \mathrm{~m}$ or $12 \mathrm{~m}$ of diameter and tree inventory $10-29.99 \mathrm{~cm} \mathrm{DBH}$ (only trees with $\mathrm{DBH} \geq 10 \mathrm{~cm}$ were measured). From the plot center to the second circle 
(medium circle), the radius was $0-14 \mathrm{~m}$ or $28 \mathrm{~m}$ of diameter, with tree inventory 30 $60 \mathrm{~cm} \mathrm{DBH} \mathrm{(Fig.} \mathrm{3).} \mathrm{From} \mathrm{plot} \mathrm{center} \mathrm{to} \mathrm{the} \mathrm{third} \mathrm{circle} \mathrm{(large} \mathrm{circle),} \mathrm{the} \mathrm{radius} \mathrm{was} \mathrm{0-}$ $20 \mathrm{~m}$ or $40 \mathrm{~m}$ of diameter, with tree inventory $>60 \mathrm{~cm} \mathrm{DBH}$. In each case, using the tape, the tree was measured at a chest height of $1.30 \mathrm{~m}$ above ground. Each measurement was done from the plot center to the north; south; east part and lastly from the center to the West according to Pearson and Brown (2005). Each recorded tree was then marked and labeled with a nail (model number 5 made by NASAFA Plc, Congo) carrying a $10 \mathrm{~cm}^{2}$ plastic label obtained from PLASCO Plc, Congo. A compass was used (model SILVA-2S, Scale 1:24000) to determine cardinal points (N-S \& E-W) or orientations of each plot. Finally, the GPS (model Garmin 60CSx) has been used to record the plot coordinates (location) in minutes, degrees and seconds. Data from each plot was then recorded (Fig. 1).

Table 1. Study sites and their characteristics. IBK: Iboubikro (Plot1, Plo2, Plot3); BLF: Blue lake forest (Plot4, Plot5, Plot6); n: Number of sampled trees by site; E: Pielou evenness index; $H^{\prime}$ : Shannon-Weaver index of species diversity (in bit); G: Basal area (in $\mathrm{m}^{2}$ $\left.\mathrm{ha}^{-1}\right) ; D^{\prime}$ : Diversity of Simpson index; K: Similarity of Sorensen index for both of two sites (in \%); SR*: Species richness; DBH: Average of diameter at breast height (in cm); Pi: Relative abundance of the species; S: Number of species

\begin{tabular}{c|c|c|c|c|c|c|c|c|c|c}
\hline Site & \multicolumn{3}{|c|}{ Flora richness } & \multicolumn{4}{c|}{ Diversity indices } & \multicolumn{2}{c|}{ Structure } & \multirow{2}{*}{ K } \\
\cline { 2 - 9 } & $\mathrm{S}$ & $n$ & $\mathrm{SR}^{*}$ & $\mathrm{H}^{\prime}$ & $P i$ & $\mathrm{E}$ & $\mathrm{D}^{\prime}$ & $\mathrm{G}$ & $\mathrm{DBH}$ & \\
\hline IBK & 17 & 52 & 52 & 2.48 & 1 & 0.89 & 0.10 & 22.31 & 27 & \\
& & & & & & & & & & 43.7 \\
BLF & 15 & 33 & 33 & 2.29 & 1 & 0.86 & 0.14 & 23.08 & 35 & \\
\hline
\end{tabular}

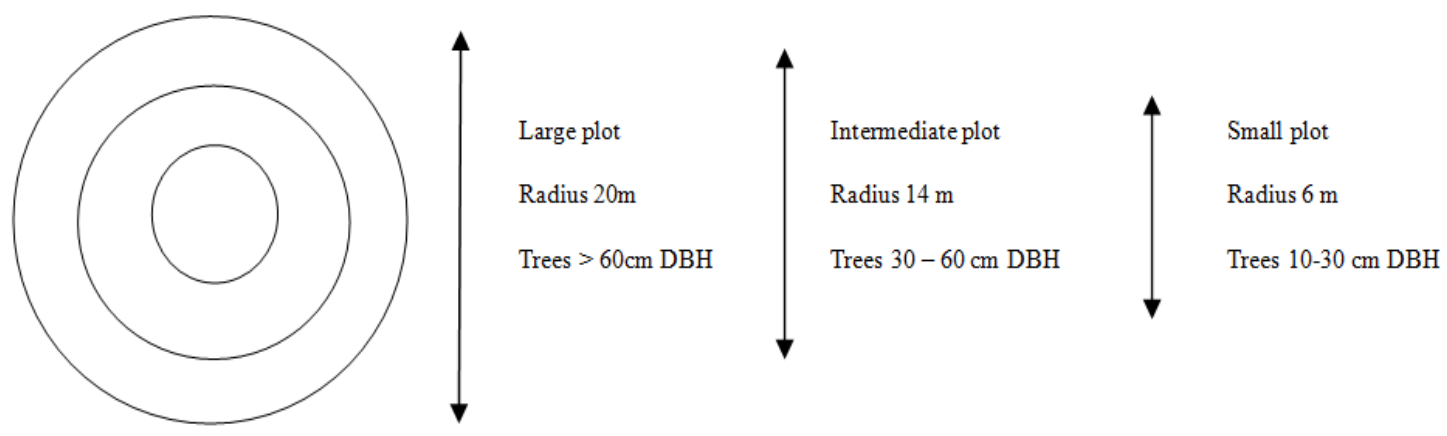

Figure 3. Sample design: Circular plot of data census in study area. The schematic diagram represents a sample plot consisting of three concentric circles

\section{Data analysis}

The floristic data was calculated in order to obtain various indices of diversity, phytogeographical determination of species and life forms as mentioned by Spellerberg and Fedor (2003). A diversity index was used since it provides detailed information on community composition and relative abundance. To know regarding the variation among plant communities in Blue lake forest and Iboubikro, ANOVA has been performed using SPSS 18.0 program. This data was analyzed using SPSS version18.0 software while the survey area map was performed with QGIS version 2 and ArcGIS 
version 9.3. We used the Shannon (Eqs. 2 and 3) and Pielou evenness (Eq. 4) and Sorensen \& Simpson's index (Eqs. 5-7), to evaluate floristic diversity and accuracy indices (Spellerberg and Fedor, 2003; CBD, 2006; Fedor and Spellerberg, 2013). Using Sorensen's similarity index (Spellerberg and Fedor, 2003; Folega et al., 2011; Ekoungoulou et al., 2017), to perform the basal area and specific richness study for the Lesio-louna forest.

(a) Relative frequency:

The relative frequency and specific contribution of each tree species and family have been performed as follows (Eq. 1):

$$
F_{(\%)}=\frac{n_{i}}{N} \times 100
$$

where $F$ is relative frequency of species and family (in $\%), n_{i}$ is the number of individual $i$ and $N$ is the total number of individuals found in the communities.

(b) Shannon-Weaver index, $H^{\prime}$ :

$$
H^{\prime}=-\sum_{i=1}^{n} P_{i} \ln P_{i}
$$

According to Shannon-Weaver's diversity equation: $H^{\prime}$ is Shannon index, $P_{i}$ is the proportion of individuals of one particular species found divided by the total number of individuals found, $\ln$ is the natural $\log , \Sigma$ is the sum of the calculations and $n$ is the number of tree species.

$P_{i}$ is calculated as follows:

$$
P_{i}=\frac{N_{i}}{N}
$$

However, where $H^{\prime}$ is the Shannon-Weaver index of species diversity, $P_{i}$ is the relative abundance of the species $I, N_{i}$ is the number of the species $i$ and $N$ is the total number of species.

(c) Pielou evenness, E:

It represents the relationship between observed diversity and the possible maximum diversity for a given number of species of tree $(N)$.

Small values of equitability represent a big importance of some dominant species.

$$
E=H^{\prime} / \ln N
$$

with:

$$
\begin{aligned}
& E=\text { Pielou evenness } \\
& H^{\prime}=\text { Shannon index } \\
& N=\text { number of species } \\
& \ln =\text { natural } \log
\end{aligned}
$$


(d) Diversity of Simpson index, $D$ ':

It gives the probability that two individuals taken at random from a population studied belong to the same species (Ekoungoulou et al., 2015). This index measures how individuals are distributed among species of a community. It is a measure of the inverse diversity.

$$
D^{\prime}=\sum\left(N_{i} / N\right)^{2}
$$

with:

$D^{\prime}=$ Simpson's index

$N i=$ number of species $i$

$N=$ total number of species

(e) Species richness, SR:

It is the total number of floristic richness (families, genus and species) in the communities studied.

(f) Similarity of Sorensen index, $K$ :

The degree of quantitative resemblance of two lists can be measured by the formula of the similarity coefficient of Sorensen (Spellerberg and Fedor, 2003; Folega et al., 2011; Ekoungoulou et al., 2017). From 2 floristic lists A and B, a designating the number of species of sample $\mathrm{A}$ and $\mathrm{b}$ designating the number of species of sample $\mathrm{B}$ and $\mathrm{c}$ designating the number of common species to both floristic lists, the coefficient of community Sorensen, $\mathrm{K}$ is calculated in the following manner:

$$
K=\frac{2 * c}{(a+b)} \times 100
$$

with:

$a=$ number of species in sample 1 ,

$b=$ number of species in sample 2 ,

$c=$ number of species common to both.

This index can used to evaluate the floristic affinities between 2 samples. If $K>50 \%$, then the two samples belong to the same plant community in the area.

(g) Basal area, $G$ :

This is a measurement taken at the DBH $(1.3 \mathrm{~m})$ of a tree above the ground and includes the complete diameter of every tree. To estimate a tree's basal area, we used the tree's DBH in inches with the following formula:

$$
G=\sum\left(D_{i}\right)^{2} \times \frac{\pi}{4}
$$

where $G=$ basal area $\left(\mathrm{m}^{2} \mathrm{ha}^{-1}\right), D_{i}=\operatorname{diameter}(\mathrm{cm})$ at $1.3 \mathrm{~m}$ above the ground and $\pi=3.14$. 


\section{Results and Discussion}

A total of 85 trees divided into 25 species and 14 families have been recorded within the six circular plots studied (Table 2). Amongst the 85 trees, 52 trees were in the diameter class of 10-29.99 cm; 28 trees in the diameter class of $30-60 \mathrm{~cm}$ and 6 trees in the diameter class $>60 \mathrm{~cm}$ (Fig. 5). The Iboubikro site (Plot1, Plot2 and Plot3) had more measured trees (52 trees) while the Blue lake forest site (Plot4, Plot5 and Plot6) with 33 trees found. At the plot level, plot 3 had more recorded trees (20 trees) followed by plot 1 with 17 trees recorded (Table 1). The average diameter at breast height (DBH) for the 6 plots studied was $30.80 \mathrm{~cm}$. Meanwhile, the average recorded diameter at breast height varied from $41.91 \mathrm{~cm}$ in plot 6 to $24.49 \mathrm{~cm}$ in plot 4 . The investigation revealed that in this ecosystem Fabaceae (20\%), Mimosaceae (16\%), Sapindaceae $(12 \%)$ and Annonaceae (9\%) where the most representative families (Fig. 4a). Millettia laurentii De Wild. (14\%), Pentaclethra eetveldeana De Wild. \& T. Durand (14\%), Eriocoelum macrocarpum Gilg ex Radlk. (8\%), Millettia pinnata Panigrahi (6\%), Sorindeia juglandifolia (A.Rich.) Planch. Ex Oliv. (6\%) and Xylopia aethiopica (Dunal) A.Rich. (6\%) was the most dominant species (Fig. 4c). In Flacourtiaceae (1\%), Euphorbiaceae $(1 \%)$ and Rubiacea $(1 \%)$ a very low proportion of relative frequency of families were found (Fig. 4a). Treculia obovoidea N.E.Br. (1\%), Oxyanthus speciosus DC. (1\%) and Macaranga barteri Mull. Arg. (1\%) had a very low proportion of species relative frequency (Fig. $4 c$ ). The revision and homogenization were also applied on the taxonomy according to the working list of all plant species (accessed 8 January 2017 from http://www.theplantlist.org and from http://www.xycol.net/index.php?categorie= $0 \&$ sess _langue $=430$ ).

Biodiversity analysis was made also by using Shannon-Weaver diversity index. For this research, the floristic biodiversity analysis between Iboubikro and Blue lake forest have been considered (Table 1). Shannon diversity index regarding six studied plots were between 2.29 and 2.48 bits (Fig. 4d). The highest Shannon index recorded was in Iboubikro site (2.48 bit), while the lowest was recorded in Blue lake forest site $(2.29$ bit). Table 1 show that Pielou's evenness index was 0.86 for Blue lake forest $(86.9 \%)$ and 0.89 for Iboubikro (89.4\%). Iboubikro site had the highest index of Shannonweaver and Pielou index compared with Blue lake forest site (Fig. 4d). An evenness index > 60\% characterized an undisturbed ecosystem (Spellerberg and Fedor, 2003; Fedor and Spellerberg, 2013). One of non-disturbance reason about Lesio-louna forest is because this ecosystem is a protected area.

Similarity of Sorensen index regarding studied sites was $43.7 \%$ (Table 1). These results show that there is a very low similarity of species between Iboubikro and Blue lake forest, and between six study plots. All species of two communities studied are not similar. The results show that in total of 25 species only 7 similar species (species common to both communities) have been recorded in Iboubikro as well as in Blue lake forest. The two sites could be totally similar if Sorensen's index was 100\% (Legendre, 2014; Koubouana et al., 2015). If this index is less than or greater than $100 \%$, it is inferred that the two ecosystems are not completely similar (Legendre, 2014).

The Simpson diversity index was ranged from 0.10 regarding Iboubikro to 0.14 for Blue lake forest (Table 1). This index will have a value of 0 to indicate the maximum diversity, and a value of 1 to indicate the minimum diversity (Folega et al., 2011; Ekoungoulou et al., 2015). In this area, an important trees biodiversity have been measured. The value of Simpson diversity index recorded show a maximum trees biodiversity in Lesio-louna forest. 


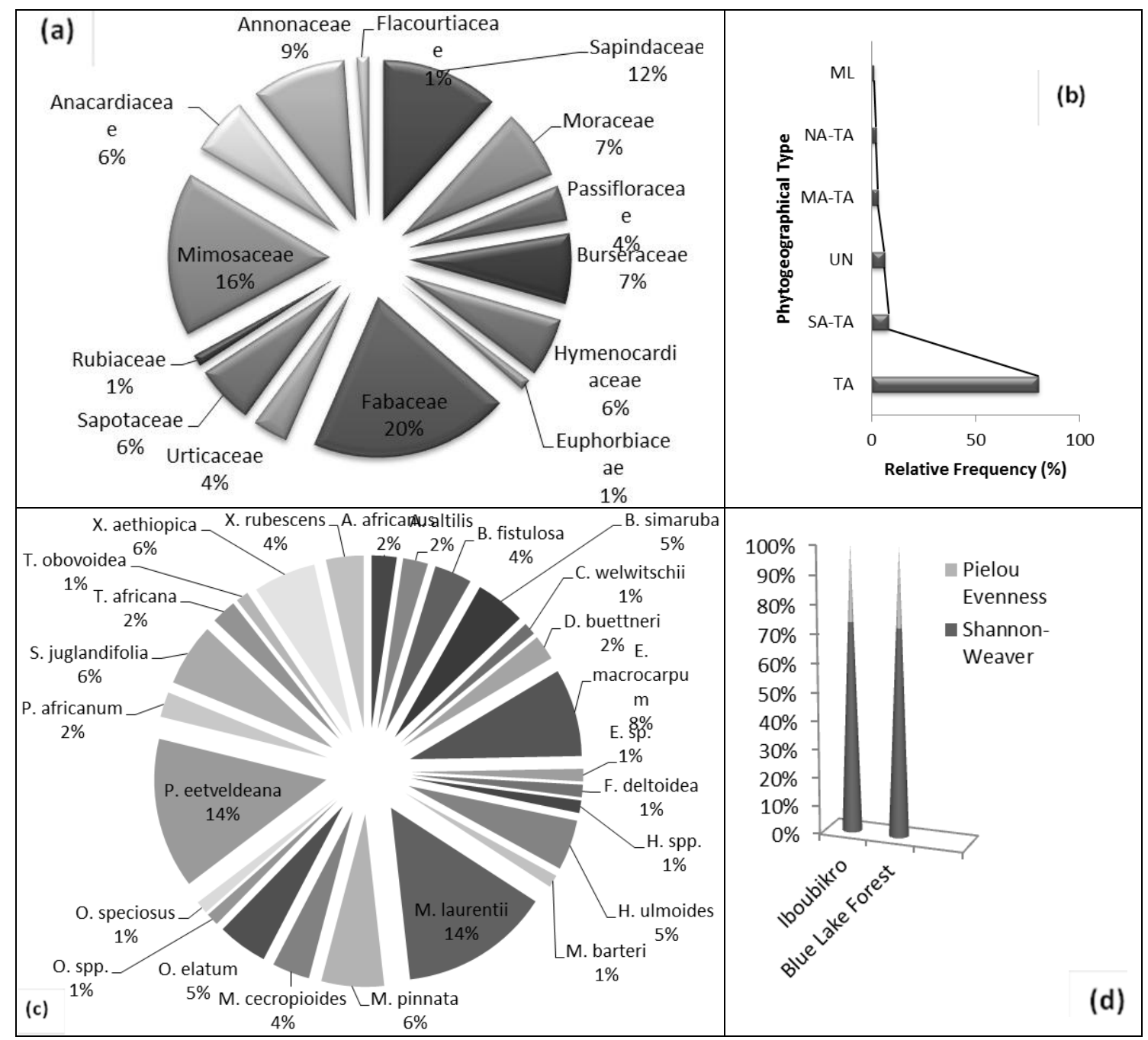

Figure 4. Floristic diversity overview of forest ecosystem: (a) Relative frequency of specific spectra families recorded in study area; (b) phytogeographical type distribution-TA: Tropical Africa Area (EPFAT Area, country-based, south of Sahara, complementary to the following),

SA: Southern Africa Area (South Africa, Namibia, Botswana, Lesotho, and Swaziland), NA: North Africa (Mauritania, Morocco, Canary IsI., Algeria, Tunisia, Libya, Egypt, and Madeira), ML: Malaysia (Tropical Asia), UN: Undetermined, and MA: Madagascar (Malagasy Republic); (c) Distribution of diversity among species taxa; (d) Variation of Shannon-Weaver diversity and Pielou Evenness indexes

Therefore, Basal area of Blue lake forest $\left(23.08 \mathrm{~m}^{2} \mathrm{ha}^{-1}\right)$ was higher compared with Iboubikro $\left(22.31 \mathrm{~m}^{2} \mathrm{ha}^{-1}\right)$ as showed in Table 1 . Basal area provided better measurement about the relative importance of tree species than simple stem count. It was obvious that dendrological parameters in Iboubikro were higher than those of Blue lake forest (Fig. 5). In order to know whether there is variation among the Iboubikro and Blue lake forest in species richness, evenness and species diversity, one way ANOVA was done using SPSS version 18.0 statistical software. The result of ANOVA performed showed that there was statistically significant difference among plant communities in species richness, evenness and species diversity at $92 \%$ confidence interval for Blue lake forest and Iboubikro (Table 2 and Fig. 4). A two sample t-test was 
done in order to know the existence of variation within a community utilizing species richness, evenness and diversity of species. The result of 2 sample t-test shows that, there is a significant difference at $92 \%$ confidence interval within community types (Table 2 and Fig. 4).
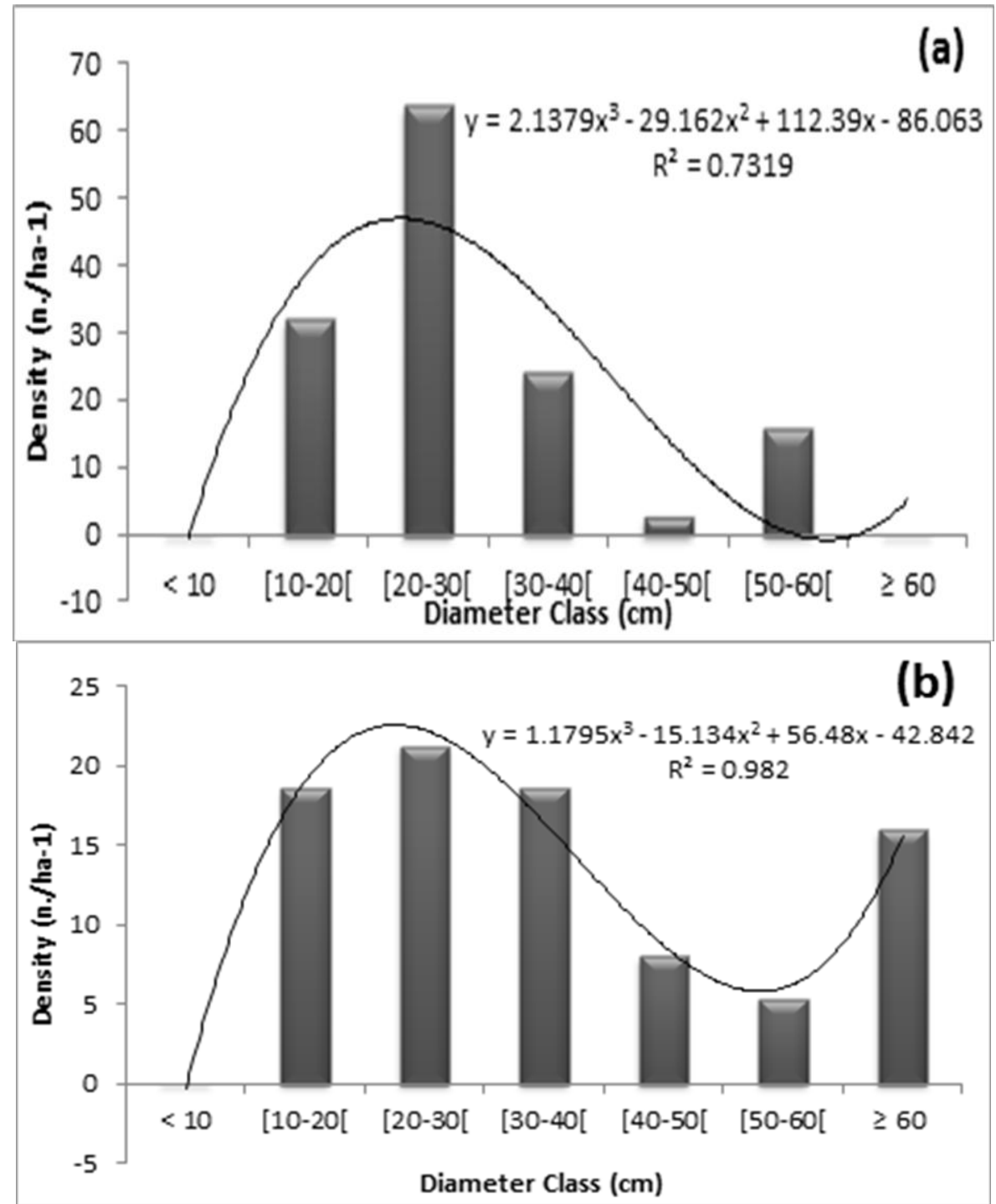

Figure 5. Diameter class distribution of trees in Blue lake forest site (a) and Iboubikro site (b)

However, on chorological level, Tropical African species (80\%) were the most important about the Phytogeographical type (Fig. 4b) followed by Southern AfricanTropical African species (8\%). Malaysian species (1\%) had a very low proportion of phytogeographical type followed by Northern African-Tropical African species (Fig. $4 b$ ). This study shows that, the Fabaceae family was dominant with 17 tree species, with relative diversity index of 20\% (Fig. 4a). Among these 17 tree species, 12 tree species were Millettia laurentii De Wild., with a diameter at breast height (DBH) ranging from 11.1- $63.1 \mathrm{~cm}$ (Table 2). This was followed by the Mimosaceae with 14 tree species of which 12 species were Pentaclethra eetveldeana De Wild. \& T. Durand, and the diameter at breast height $(\mathrm{DBH})$ ranging from $10.9-59.2 \mathrm{~cm}$. Other regular families 
included the Sapindaceae with 10 tree species; Annonaceae with 8 tree species; Euphorbiaceae, Flacourtiaceae and Rubiaceae with one tree species each (Fig. 4a). Fabaceae and Mimosoideae are dominant in this forest ecosystem because this environment is favourable for them. The trees from these families (Fabaceae and Mimosaceae) have a rapid growth than others, because they receive more light than other trees. These are trees that usually have an abundant canopy. Fabaceae and Mimosoideae are the Leguminosae (particularity absorbs the atmospheric nitrogen through nodules located in its roots). Leguminosae enrich the soil with nitrogen. The study show that the number of families varies from one site to another and from one plot to another. The trees of this forest are not producing since the inception of the Lesio-louna project, to sustainable forest management, also for the flora conservation. Any logging is strictly forbidden in Lesio-louna area (PLL, 2010).

Table 2. Distribution of species recorded in the moist forest of Lesio-louna (study area) by family. Phytogeographical type has been provided by African Plants Database (version 3.4.0) of Conservatoire et Jardin botaniques de la ville de Geneve, Switzerland \& South African National Biodiversity Institute, Pretoria (Retrieved 6 January 2017 at http://www.ville-ge.ch/musinfo/bd/cjb/africa/), and Global plants (Accessed 6 January 2017 at http://plants.jstor.org/). DBH: diameter at breast height (in cm), $n$ : Number of tree species recorded, PT: Phytogeographical type, TA: Tropical Africa Area (EPFAT Area, countrybased, south of Sahara, complementary to the following), SA: Southern Africa Area (South Africa, Namibia, Botswana, Lesotho, and Swaziland), NA: North Africa (Mauritania, Morocco, Canary IsI., Algeria, Tunisia, Libya, Egypt, and Madeira), ML: Malaysia (Tropical Asia), UN: Undetermined, and MA: Madagascar (Malagasy Republic)

\begin{tabular}{llccc}
\hline Species & Family & PT & $n$ & DBH range \\
\hline Allophylus africanus P.Beauv. & Sapindaceae & SA-TA & 2 & $25.6-27.5$ \\
$\begin{array}{l}\text { Artocarpus altilis (Parkinson ex F.A.Zorn) } \\
\text { Fosberg }\end{array}$ & Moraceae & NA-TA & 2 & $21.6-31.4$ \\
Barteria fistulosa Mast. & Passifloraceae & TA & 3 & $14.6-21.2$ \\
Bursera simaruba (L.) Sarg. & Burseraceae & TA & 4 & $29.8-79.0$ \\
Caloncoba welwitschii (Oliv.) Gilg & Flacourtiaceae & TA & 1 & 18.3 \\
Dacryodes buettneri (Engl.) H.J.Lam & Burseraceae & TA & 2 & $22.2-24.3$ \\
Eriocoelum macrocarpum Gilg ex Radlk. & Sapindaceae & TA & 7 & $13.5-25.9$ \\
Eriocoelum spp. & Sapindaceae & TA & 1 & 41.1 \\
Ficus deltoidea Jack & Moraceae & ML & 1 & 17.7 \\
Hymenocardia spp. & Hymenocardiaceae & TA & 1 & 28.5 \\
Hymenocardia ulmoides Oliv. & Hymenocardiaceae & SA-TA & 4 & $16.9-50.3$ \\
Macaranga barteri Müll.Arg. & Euphorbiaceae & TA & 1 & 10.3 \\
Millettia laurentii De Wild. & Fabaceae & TA & 12 & $11.1-63.1$ \\
Millettia pinnata (L.) Panigrahi & Fabaceae & UN & 5 & $32.0-65.7$ \\
\hline
\end{tabular}




\begin{tabular}{llccc}
\hline Musanga cecropioides R.Br. ex Tedlie & Urticaceae & TA & 3 & $12.2-35.2$ \\
Omphalocarpum elatum Miers & Sapotaceae & TA & 4 & $15.4-34.2$ \\
Omphalocarpum spp. & Sapotaceae & TA & 1 & 10.6 \\
Oxyanthus speciosus DC. & Rubiaceae & SA-TA & 1 & 84.3 \\
Pentaclethra eetveldeana De Wild. \& T.Durand & Mimosaceae & TA & 12 & $10.9-59.2$ \\
Piptadeniastrum africanum (Hook.f.) Brenan & Mimosaceae & TA & 2 & $22.8-26.0$ \\
Sorindeia juglandifolia (A.Rich.) Planch. ex Oliv. & Anacardiaceae & TA & 5 & $12.9-26.5$ \\
Treculia africana Decne. ex Trécul & Moraceae & MA-TA & 2 & $21.1-30.8$ \\
Treculia obovoidea N.E.Br. & Moraceae & TA & 1 & 17.3 \\
Xylopia aethiopica (Dunal) A.Rich. & Annonaceae & TA & 5 & $11.6-60.5$ \\
Xylopia rubescens Oliv. & Annonaceae & TA & 3 & $20.3-36.6$ \\
\hline
\end{tabular}

With regard to the phytogeographical type of species, this study shows that most of species recorded in Lesio-louna forest are from tropical Africa area, precisely the South of Sahara's countries (Table 2). The countries from South of Sahara (Africa) are dominated by the moist forests and some dry forests.

In the circular plots studied, 52 trees belonged to the diameter class $10-29.99 \mathrm{~cm}$ while 28 trees belonged to the diameter class $30-60 \mathrm{~cm}$ and 6 trees to the diameter class $>60 \mathrm{~cm}$ could be because the forest is to recover with a considerable regeneration as asserted by PLL (2010). Figure 5 shows that, regarding the DBH classes of trees, an important number of trees have been recorded with the diameter class $20-30 \mathrm{~cm}$ for Iboubikro site as well as for Blue Lake Forest site compared to others diameter classes. In this study a measurement of more trees with low DBH and few trees with high DBH have been done (Table 2 and Fig. 5). The horizontal growth of these trees depends on the vertical growth. Observation also showed the regeneration in Lesio-louna edge by the forest that moves towards Savannah.

More trees have been recorded in Iboubikro site (52 trees) as compared with the Blue lake site (33 trees), that can be by the fact that Blue lake forest is located in a cavity trough which is like a recess. Trees of this ecosystem (Blue lake forest) receive less light, because the forest is surrounded by hills. It is well known that floristic composition is determined by ecological factors. Other reason is the fact that Blue lake forest is often visited by tourists (disturbance of the ecosystem by anthropogenic activities). Therefore, it influences biodiversity patterns at both local and a regional scale further reflects both human and natural disturbances. Thus, in this ecosystem, floristic characteristics and biodiversity patterns coincide with the climate factors and anthropogenic actions. This study showed a variation in the DBH (diameter at breast height) and tree species amongst the plots because there is a forest atmosphere and individuals are heterogeneous (Fig. 5).

Similarly, studying floristic biodiversity and natural regeneration in three forest islands, Koubouana (2015) found 120 species and 47 families. These included the Rubiaceae (25.6 to $34.2 \%$ ) and the Fabaceae (5.9 to $13.9 \%$ ); characteristic species 
density varying from 0.7 to 60 trees $^{-1}$ and biological diversity for Shannon index (H') averaged $1.9 \pm 0.3$ for Woody as against $3.5 \pm 0.25$ for the total flora (Koubouana, 2015). In the study by Koubouana (2015), the various indices showed their referral ecosystem had a low floristic diversity accompanied by heterogeneity and dominance in floristic composition.

In a related study Kimpouni (2008) asserted that, the species Aucoumea klaineana Pierre exhibited a highly heterogeneous and spatio-temporal floristic diversity in its specific composition. Their study concluded that, though Aucoumea klaineana Pierre is the characteristic and dominant element for this feature, its dynamics has a regressive evolution in relation to the step of development. According to their study, the Fabaceae has a relative diversity index of $18.31 \%$. This does not tally with our study which found the relative diversity index for Fabaceae to be $20 \%$ (Fig. $4 a$ ).

In this study, floristic heterogeneity between Iboubikro and Blue lake forest was studied from structural analysis using the Sorensen similarity index. The result showed on the one hand that the sampled sites of measurement belong to the forest type and, on the other hand, that there is floristic variability due to the substrate variation as mentioned by PLL (2010) and Koubouana (2015). The different sites (Iboubikro and Blue lake forest) inventoried belong to the same plot type (with various area and climate condition) highlighted by the Sorensen similarity index. This cross-site heterogeneity is also observed in the site tailgates. The variability of edaphic factors such as soil composition, dewatered and hydromorphic soils and others could be an indicator concerning this kind of floristic richness about Lesio-louna protected area.

In Lesio-louna's Teke-plateau, along of streams and rivers, are the galleries forests (moist forest), but it varies considerably from one point to another of the hydrographic network (PLL, 2010). Near the heads of rivers, these galleries can be very narrow and reduced to a simple screen of trees, but they can also be continuity with shreds of dry forests hooks a slope shape. In this case, it is sometimes very difficult to draw a strict line between the riparian forest (gallery forest) and dry forest or secondary forest. In Lesio-louna, narrow galleries however is a rather special environment very different from the great forest. In fact, they are composed of two strips joined together back-toback housing and a narrow strip of dense humid vegetation along a stream. When the stream that feeds the forest is enclosed between two steep banks, as it often happens in the upper part of the stream, the undergrowth may however be relatively dry. In general, even in very narrow tunnels, measuring no more than 20 or $30 \mathrm{~m}$ wide, however there are two areas. From both sides of the river, there is a central very wet and susceptible to some flooding during heavy flood area (Ekoungoulou, 2014).

A distance of rivers, on the foot of the hill lays a marginal area which is never flooded but the vegetation is more resistant to drought (Ekoungoulou et al., 2015). Further downstream, these galleries of Lesio-louna widen, and their edges depart, leaving more room for the central zone. Imperceptibly merges riparian gallery then in the great forest. Ecological difference between a gallery and a great forest is not always very clear, but in extreme cases it is well marked (Ekoungoulou et al., 2015). In a narrow gallery forest, vegetation undergrowth, at least in the wetland is generally very dense because of the proximity of the edge. Here, the microclimate is not as stable as in the great forest. The canopy is rarely continues (Nkounkou, 2003). It receives a very important side lighting and is much more exposed to the wind, so to drying, the canopy of the rainforest. Epiphytes are generally concentrated over the central stream and vines are extremely abundant, they constitute a very significant proportion of plant biomass (FAO, 2008). Another very important aspect of moist forests is related to the fact that 
they represent a quasi-linear medium. Animals that live in these galleries are forced to make important trips. Many species of forest, especially birds, avoid narrow galleries forests or moist forests (PLL, 2010).

Thus, understanding the factors that control species distributions and forest composition is a central issue in ecology and conservation because floristic diversity of Lesio-louna is influenced by ecological factor. This study has allowed to deduct that the advance of the forest to savannah in Lesio-louna and observed during our field work is may be caused by the wealth of organic matter soil. This wealth of organic matter soil can be by the fact that the forest is dominance of Fabaceae ( $20 \%$ of relative diversity index) and Mimosaceae (16\% of relative diversity index). Many tree species from Fabaceae and Mimosaceae have been recorded during this study in natural forest of Lesio-louna. The species from Fabaceae and Mimosaceae families enrich the soil with nitrogen, and nitrogen is important for the nutrition of plants. Given the significant differences in floristic diversity, Lesio-louna forest ecosystem could play an important role in climate change mitigation and thus could provide a carbon sink in all Tekeplateau, and also in the whole basin forest of Central Africa (Congo Basin). However, knowing the Lesio-louna's floristic richness by this study, this forest ecosystem is important to contribute to the global environmental protection and support the reducing emissions from deforestation and forest degradation, and forest conservation, sustainable management of forest, and enhancement of forest carbon stocks (REDD ${ }^{+}$) guidelines as set the Kyoto protocol. Also, in this ecosystem the growth of the forest to savanna is remarkable, because several species of bush land are found in the forest edge and even in the middle of forest as observed by PLL (2010).

Moreover, in this study area, the reconstitution of the wood stand can be characterized by diversity, basal area and the distribution of individuals in diameter classes. Diversity establishes links between the richness and the abundance of individuals; it reflects the degree of heterogeneity or stability of vegetation in Lesio-louna. The basal surface reflects the dynamism of vegetation and recovery speed. Plant diversity can therefore be integrated several parameters such as the structure and dynamics of vegetation. The relationship between diversity and structure in a community can be associated with various changes: diversity is a function of the structure dynamics and the structure diversity is a function of dynamic. This shows interest to appreciate the diversity of Congolese forest ecosystems for their sustainable management.

\section{Conclusion}

The vegetation of Central Africa is largely composed of Congo drainage basin and contiguous humid closed canopy forests less well known, large areas of savannah and forest-savannah mosaics often composed of forest groves either along the river bank or resulting from ancient local human activities. In Lesio-louna forest (Republic of Congo), the floristic diversity presented a dynamism and floristic richness very considerable in its specific composition, from Iboubikro to Blue Lake Forest sites. The number of trees recorded in Iboubikro site was important compared to the number of trees recorded in Blue Lake Forest site. In this Lesio-louna forest, DBH of trees vary from one plot to another and the number of trees species sampled varies from plot to plot. There is observation of a heterogeneous floristic diversity in this forest ecosystem. This study may enable us to contribute in the promotion of Lesio-louna forest ecosystem, which includes species with importance for humanity. Increasing 
knowledge of plants distributions in Congo demonstrated clear smaller-scale variation in forest composition and its relationship with environmental conditions, notably rainfall but also geological substrate and soil, or a combination of soil and rainfall. Also, in this forest there is abundance of trees with large diameter which was the main reason for these differences. Generally, the Lesio-louna forest is in the regeneration period, and can be a considerable carbon sink for the Republic of Congo and the world. Knowing the floristic richness of Lesio-louna by this study, this moist forest is an important ecosystem to contribute to the global climate change mitigation and support the REDD+ process.

Acknowledgments. The research work was supported by the National Key Research and Development Project (2017YFD0600106) from China, China Scholarship Council (see www.csc.edu.cn) and Beijing Forestry University (see www.bjfu.edu.cn). We greatly thank MEFDD-REDD+/WRI Project and Lesiolouna Project (PLL) for their assistance during the research period. It is a pleasure to acknowledge Locky Okandza from The Aspinall Foundation for his technical assistance during data collection in Lesio-louna forest. The authors gratefully acknowledge Jean Bafinga from The Aspinall Foundation and Thechel Ekoungoulou from Food and Agriculture Organization of the United Nations (FAO) for their contribution regarding this study. We also thank an anonymous referee for insightful comments on a previous version of the manuscript.

Conflict of interests. The authors declare that there is no conflict of interests regarding this paper.

\section{REFERENCES}

[1] ANAC, National Agency of Congo's Civil Aviation (2013): Annual Report on Congolese Meteorological National Situation. - National Agency of Congo's Civil Aviation. Brazzaville, Congo (in French).

[2] CBD, Convention on Biological Diversity (2006): Sustaining Life on Earth. Global Diversity Outlook. - No: UNEP/CBD/COP/8/12., Nairobi, Kenya.

[3] Chao, A., Shen, T. J. (2003): Nonparametric estimation of Shannon's index of diversity when there are unseen species in sample. - Environmental and Ecological Statistics 10(4): 429-443.

[4] Chen, K. S., Li, J. Q. (2011): A study of the flora in the east part of Amber Mountain National Park, Madagascar. - Journal of Agriculture, Biotechnology and Ecology 4(2): 100-109.

[5] Djuikouo, M. N. K., Doucet, J. L., Nguembou, C. K., Lewis, S. L., Sonke, B. (2010): Diversity and aboveground biomass in three tropical forest types in the Dja Biosphere Reserve, Cameroon. - African Journal of Ecology 48: 1053-1063.

[6] Duveiller, G., Defourny, P., Desclee, B., Mayaux, P. (2008): Deforestation in Central Africa: Estimates at regional, national and landscape levels by advanced processing of systematically-distributed Landsat extracts. - Remote Sensing of Environment 112: 19691981.

[7] Ekoungoulou, R. (2014): Carbon Stocks Evaluation in Tropical Forest, Congo. Carbon Stocks in Forest Ecosystems. - Lambert Academic Publishing, Saarbrucken, Germany.

[8] Ekoungoulou, R., Liu, X., Ifo, S. A., Loumeto, J. J., Folega, F. (2014a): Carbon stock estimation in secondary forest and gallery forest of Congo using allometric equations. International Journal of Scientific \& Technology Research 3(3): 465-474. 
[9] Ekoungoulou, R, Liu, X., Loumeto, J. J., Ifo, S. A., Bocko, Y. E., Koula, F. E., Niu, S. (2014b): Tree allometry in tropical forest of Congo for carbon stocks estimation in aboveground biomass. - Open Journal of Forestry 4(5): 481-491.

[10] Ekoungoulou, R., Niu, S., Loumeto, J. J., Ifo, S. A., Bocko, Y. E., Mikieleko, F. E. K., Guiekisse, E. D. M., Senou, H., Liu, X. (2015): Evaluating the carbon stock in above-and below-ground biomass in a moist central African forest. - Applied Ecology and Environmental Sciences 3(2): 51-59.

[11] Ekoungoulou, R, Nzala, D, Liu X, Niu, S. (2017): Ecological and structural analyses of trees in an evergreen lowland Congo basin forest. - International Journal of Biology 10(1): 31-43.

[12] Ernst, C., Mayaux, P., Verhegghen, A., Bodart, C., Christophe, M., Defourny, P. (2013): National forest cover change in Congo Basin: Deforestation, reforestation, degradation and regeneration for the years 1990, 2000 and 2005. - Global Change Biology 19(4): 1173-1187.

[13] FAO, Food and Agriculture Organization of the United Nations (2008): Congo basin forests. Forests state. - Food and Agriculture Organization of the United Nations. Rome, Italy.

[14] FAO, Food and Agriculture Organization of the United Nations (2016): State of the World's Forests. - Food and Agriculture Organization of the United Nations (UNFAO), Rome, Italy.

[15] Fayolle, A, Picard, N., Doucet, J. L., Swaine, M. D., Bayol, N., Benedet, F., GourletFleury, S. (2014a): A new insight in the structure, composition and functioning of central African moist forests. - Forest Ecology and Management 329: 195-205.

[16] Fayolle, A., Swaine, M. D., Bastin, J. F., Bourland, N., Comiskey, J. A., Dauby, G., Doucet, J. L., Gillet, J. F., Gourlet-Fleury, S., Hardy, O. J., Kirunda B., Kouame, F. N., Plumptre, A. J. (2014b): Patterns of tree species composition across tropical African forests. - Journal of Biogeography 41: 2320-2331.

[17] Fedor, P. J., Spellerberg, I. F. (2013): Shannon-Wiener Index. Reference Module. - Earth Systems Environmental Sciences 1: 1-4.

[18] Folega, F., Kperkouma, W., Zhang, C. Y., Zhao, X. H., Koffi, A. (2011): Woody vegetation of protected areas in Northern Togo. Case of Barkoissi, Galangashi and OtiKeran: Ecological and Structure Analyses of Plant Communities. - Forestry Study in China 13(1): 23-35.

[19] Folega, F., Zhang, C. Y., Woegan, Y. A., Wala, K., Dourma, M., Batawila, K., Seburanga, J. L., Zhao, X. H., Akpagana, K. (2014): Structure and ecology of forest plant community in Togo. - Journal of Tropical Forest Science 26(2): 225-239.

[20] Kimpouni, V., Loumeto, J. J., Mizingou, J. (2008): Floristic diversity of forest facies on the Congolese littoral's Aucoumea klaineana (Okoumé). - Acta Botanica Galica: Botany: Botany Letters 155(3): 323-334 (in French).

[21] Koubouana, F., Ifo, S. A., Moutsambote, J. M., Banzouzi, R. R. F., Akobe, A., Ikama, C. O., Mantota A. B., Dzai, S., Mbemba, M. (2015): Structure and flora tree biodiversity in Congo Basin: Case of a secondary tropical forest in southwest of Congo-Brazzaville. Research in Plant Sciences 3(3): 49-60.

[22] Legendre, P. (2014): Interpreting the replacement and richness difference components of beta diversity. - Global Ecology and Biogeography 23: 1324-1334.

[23] Mukete, B., Sun, Y. (2014): Assessing the effectiveness of urban nature reserves on biodiversity conservation. - Applied Ecology and Environmental Sciences 2(6): 130-134.

[24] Ngomanda, A., Lebamba, J., Engone-Obiang, N. L., Lepengue, N., M'Batchi, B. (2013): Characterization of forest-savannah mosaics'dry biomass in Okouma and Bagombe plateaus, Southeastern Gabon. - Journal of Applied Biosciences 68: 5417-5425 (in French). 
[25] Nkounkou, J. S. (2003): Lesio-louna sanctuary flora. Pedagogic mission report. Gorilla protection project. Faculty of sciences. - Marien Ngouabi University, Brazzaville, Republic of Congo (in French).

[26] Nzala, D., Miankodila, P. (2002): Trees and green spaces in Brazzaville (Congo). - Bois et Forêts des Tropiques 272(2): 88-92. (in French).

[27] Ouedraogo, D. Y., Fayolle, A., Daïnou, K., Demaret, C., Bourland, N., Lagoute, P., Doucet, J. L. (2014): Enrichment of logging gaps with a high conservation value species (Pericopsis elata) in a Central African moist forest. - Forests 5(12): 3031-3047.

[28] Pearson, T, Brown, S. (2005): Carbon measurement guide for the forests and grasslands. Winrock International, Arlington, VA, USA (in French).

[29] PLL, Lesio-louna Project (2010): Annual Report of Lesio-louna Project. Ministry of Forest Economy and Sustainable Development. - The Aspinall Foundation, Brazzaville, Congo (in French).

[30] Spellerberg, I. F., Fedor, P. J. (2003): A tribute to Claude Shannon (1916-2001) and a plea for more rigorous use of species richness, species diversity and the Shannon-Wiener Index. - Global Ecology and Biogeography 12(3): 177-179.

[31] Yoka, J., Amiaud. B., Epron, D, Loumeto, J. J, Vouidibio, J. (2013): Floristic Analysis of the Mbomo's Palm Grove Undergrowth in the Congolese Cuvette (Republic of Congo). Annales des Sciences Agronomiques 17(2): 161-178 (in French). 